\title{
Chiasma redistribution in presence of supernumerary chromosome segments in grasshoppers: dependence on the size of the extra segment
}

Jesús Navas-Castillo, Josefa Cabrero and Juan Pedro M. Camacho

\author{
Departamento de Biología Animal, Ecología y \\ Genética, Facultad de Ciencias, Universidad de \\ Granada, 18071 Granada, Spain.
}

\begin{abstract}
The presence of two different supernumerary chromosome segments in each of four bivalents of the grasshopper Chorthippus binotatus permitted us to test confidently the effects of such extra material on chiasma distribution in the bivalents carrying them, since the same bivalent could carry any of two extra segments differing in nature, size, chromosomal location and $\mathbf{C}$-banding response. All extra segments analysed modified significantly the chiasma distribution pattern, so that chiasmata formed preferentially in the furthest chromosomal regions from the extra segment. The significant difference in the intensity of this effect observed for the two extra segments on the $M_{5}$ bivalent, however, is presumably due to their very different size, which demonstrates a direct dependence of the intensity of the chiasma redistribution on the size of the extra segment.
\end{abstract}

\section{INTRODUCTION}

In a previous paper (Navas-Castillo et al., 1985) we demonstrated that the presence of supernumerary chromosome segments in grasshoppers leads to a chiasma redistribution in the carrier bivalents independently of both their location on the chromosome and their C-banding reaction. Thus chiasmata are formed preferentially in the furthest chromosome regions from the extra segment, a fact also observed by John and King (1985) and de la Torre et al. (1986). In this paper we analyse such effect in Chorthippus binotatus, a grasshopper species which shows two types of extra segment in each of the $\mathbf{M}_{5}, \mathbf{M}_{6}, \mathbf{M}_{7}$ and $\mathrm{S}_{8}$ chromosomes (Cabrero et al., 1986) differing each other by size and/or C-banding reaction. This permitted us to test the possible dependence of the intensity of chiasma redistribution on the size of the extra segment, a possibility which was suggested in our previous study (Navas-Castillo et al., 1985). Here we analyse the effects on chiasma distribution produced by some extra segments located in the same bivalent but differing in size. Thus, a same chiasma distribution pattern could be tested in presence of two different extra segments.
MATERIALS AND METHODS

Adult males of Chorthippus binotatus were collected at several localities in the Sierra Nevada (Granada, Spain) (see Cabrero et al., 1986). Testes were fixed in $1: 3$ acetic ethanol and C-banded by the technique described in Camacho et al. (1984).

\section{RESULTS}

Both extra segments on the $\mathbf{M}_{5}$ chromosome are distally located but show different $\mathrm{C}$-banding reaction and size (see figs. 1 and 2 in Cabrero et al., 1986). While the smaller (s) is darkly C-banded, the larger (S) is darkly C-banded only in its proximal and distal regions. Table 1 shows chiasma distribution at diplotene in $\mathbf{M}_{5}$ bivalents from standard males (BB), heterozygous males for the ssegment (Bs) and heterozygous males for the Ssegment (BS). Three zones have been distinguished for chiasma formation, following the same criterion that in Navas-Castillo et al. (1985).

The presence of the small extra segment influences chiasma distribution decreasing drastically the frequency of distal chiasmata, increasing very much that of interstitial ones and 
Table 1 Chiasma distribution in three different types of $\mathbf{M}_{5}$ bivalent of Chorthippus biontatus. Three zones have been distinguished for chiasma formation: proximal (P), interstitial (I) and distal (D)

\begin{tabular}{lllll}
\hline $\begin{array}{l}\text { Type of } \mathrm{M}_{5} \\
\text { bivalent }\end{array}$ & $\mathrm{P}$ & $\mathrm{I}$ & $\mathrm{D}$ & $\begin{array}{l}\text { Total diplotene } \\
\text { cells analysed }\end{array}$ \\
\hline BB & $46(16 \cdot 61 \%)$ & $112(40 \cdot 43 \%)$ & $119(42 \cdot 96 \%)$ & 277 \\
Bs & $12(26 \cdot 09 \%)$ & $32(69 \cdot 57 \%)$ & $2(4 \cdot 35 \%)$ & 46 \\
BS & $39(56 \cdot 52 \%)$ & $30(43 \cdot 48 \%)$ & - & 69 \\
\hline
\end{tabular}

increasing slightly the frequency of proximal chiasmata. A $\chi^{2}$ test comparing chiasma distribution in $\mathrm{BB}$ and Bs bivalents demonstrated significant differences for these three locations $\left(\chi_{(2)}^{2}=25 \cdot 18\right.$, $P<0.001)$. When interstitial and distal chiasma locations are grouped, however, the $\chi^{2}$ test did not show significant difference $\left(\chi_{(1)}^{2}=3 \cdot 61, P: 0 \cdot 05\right.$ $0 \cdot 10)$. This demonstrates that the effect of the small extra segment is restricted to distal and interstitial chromosome regions. On the contrary, the effect of the large extra segment $(\mathrm{S})$ is more severe since it abolishes distal chiasmata and raise very much the frequency of proximal chiasmata. Thus, when chiasma distribution patterns (grouping interstitial and distal chiasmata) are compared between BB and $\mathrm{BS}$ bivalents, they are significantly different $\left(\chi_{(1)}^{2}=45.36, P<0.001\right)$. This demonstrates that the effect on chiasma distribution produced by the large extra segment on $\mathbf{M}_{5}$ is stronger than that produced by the small one so that chiasma redistribution reaches proximal regions. A $\chi^{2}$ test comparing the frequency of proximal versus interstitial plus distal chiasmata between Bs and BS bivalents demonstrated that chiasmata are located significantly further away from the large S-segment than the small s-segment $\left(\chi_{(1)}^{2}=9 \cdot 16, P: 0 \cdot 001-\right.$ $0.01)$. Thus, although the small supernumerary segment produces slight, but significant, effects on chiasma distribution on the $\mathbf{M}_{5}$ bivalent, the presence of the large one determines significantly more intense effects.

One of the two extra segments found on the $\mathrm{M}_{6}$ chromosome is euchromatic (E) and distally located, while the other (I) is heterochromatic, darkly C-banded and interstitially located (see figs. 3-5 and 8 in Cabrero et al., 1986). Table 2 shows chiasma distribution in three types of $\mathbf{M}_{6}$ bivalents, specifically $\mathrm{BB}, \mathrm{BI}$ and $\mathrm{BE}$.

The presence of the I-segment abolishes chiasma formation on distal $\mathbf{M}_{6}$ regions and increases significantly the frequency of proximal and interstitial chiasmata $\left(\chi_{(1)}^{2}=11.59, P<0.001\right)$. Likewise, the euchromatic distal E-segment produces a significant chiasma redistribution $\left(\chi_{(2)}^{\frac{2}{2}}=\right.$ $23 \cdot 13, P<0 \cdot 001$ ), increasing chiasma frequency in proximal and interstitial regions and at the same time decreasing the frequency of distal chiasmata. A contingency $\chi^{2}$ test applied to proximal versus interstitial plus distal chiasmata demonstrated that $\mathrm{BI}$ and $\mathrm{BE} \mathrm{M}_{6}$ bivalents show similar chiasma distribution $\left(\chi_{(1)}^{2}=0, P=1\right)$.

While both extra segments on the $\mathbf{M}_{7}$ chromosome are distally located, they are slightly different from each other in size and C-banding reaction (see figs. 5 and 6 in Cabrero et al., 1986). One of them (S) is lightly C-banded and slightly larger than the other (s) which is darkly C-banded. Table 3 shows chiasma distribution on three types of $M_{7}$ bivalents: basic (BB), heterozygous for the ssegment (Bs) and heterozygous for the S-segment (BS).

Contingency $\chi^{2}$ tests demonstrated that Bs and BS bivalents shows significantly less distal but more proximal and interstitial chiasmata than $\mathrm{BB}$ ones $\left(\chi_{(1)}^{2}=17.67, P<0.001\right.$ for BB/Bs, and $\chi_{(1)}^{2}=$ $33.59, P<0.001$ for $\mathrm{BB} / \mathrm{BS})$. Bs and BS bivalents,

Table 2 Chiasma distribution on three types of $M_{6}$ bivalents: basic (BB), heterozygous for the interstitial heterochromatic extra segment (BI) and heterozygous for the distal euchromatic extra segment (BE). P: proximal, I: interstitial, D: distal, S: extra segment assocations

\begin{tabular}{llrlll}
\hline $\begin{array}{l}\text { Type of } \\
\text { bivalent }\end{array}$ & \multicolumn{2}{l}{$\begin{array}{l}\text { Chiasma location } \\
\text { P }\end{array}$} & \multicolumn{1}{l}{ I } & D & \multicolumn{2}{l}{$\begin{array}{l}\text { Total diplotene } \\
\text { cells analysed }\end{array}$} \\
\hline BB & $39(11 \cdot 71 \%)$ & $101(30 \cdot 33 \%)$ & $193(57.96 \%)$ & - & 333 \\
BI & $11(35.48 \%)$ & $20(64 \cdot 52 \%)$ & - & - & 31 \\
BE & $10(35 \cdot 71 \%)$ & $14(50 \cdot 00 \%)$ & $4(14.29 \%)$ & 23 & $28(+23)$ \\
\hline
\end{tabular}


Table 3 Chiasma distribution on three types of $M_{7}$ bivalents: BB, Bs and BS. P: proximal, I: interstitial, D: distal, S: extra segment associations

\begin{tabular}{|c|c|c|c|c|c|}
\hline \multirow{2}{*}{$\begin{array}{l}\text { Type of } \mathbf{M}_{7} \\
\text { bivalent }\end{array}$} & \multicolumn{4}{|c|}{ Chiasma location } & \multirow{2}{*}{$\begin{array}{l}\text { Total diplotene } \\
\text { cells analysed }\end{array}$} \\
\hline & $\mathbf{P}$ & I & $\mathrm{D}$ & $\mathbf{S}$ & \\
\hline BB & $34(11.97 \%)$ & $109(38 \cdot 38 \%)$ & $141(49 \cdot 65 \%)$ & - & 284 \\
\hline Bs & $18(36 \cdot 73 \%)$ & $31(63 \cdot 27 \%)$ & - & 14 & $49(+14)$ \\
\hline BS & $23(46.94 \%)$ & $23(46 \cdot 94 \%)$ & $3(6 \cdot 12 \%)$ & - & 49 \\
\hline
\end{tabular}

however, showed a similar pattern of chiasma distribution $\left(\chi_{(1)}^{2}=0 \cdot 67, P: 0 \cdot 3-0 \cdot 5\right)$. Thus, these two segments being only slightly different in size produce comparable chiasma redistributions.

The two extra heterochromatic segments observed on $\mathrm{S}_{8}$ bivalents are different in chromosome location and C-banding reaction (see figs. 2 and 5 in Cabrero et al., 1986). One is distal and darkly C-banded (D) and the other is proximal and does not $\mathrm{C}$-band $(\mathrm{P})$. Table 4 shows chiasma distribution patterns in $B B, B D$ and $B P \quad S_{8}$ bivalents.

The D-segment produces a significant decrease in the frequency of distal chiasmata paralleled by increases in those of proximal and interstitial ones $\left(\chi_{(2)}^{2}=16 \cdot 66 . P<0 \cdot 001\right)$. The P-segment abolishes proximal chiasmata, decreases the frequency of interstitial chiasmata and increases that of distal ones $\left(\chi_{(1)}^{2}=6 \cdot 68, P: 0.001-0 \cdot 01\right)$.

\section{DISCUSSION}

Chiasma redistribution in bivalents carrying supernumerary chromosome segments has been observed in all cases analysed, although differences in the intensity of the effect have been noticed in some cases (Navas-Castillo et al., 1985). These chiasma redistributions have been deduced by studying extra segments with different chromosomal locations, C-banding response and their sites on different bivalents from different species. Thus the heterogeneity of the extra segments sample could minimise the results obtained. In the present study, however, all analysed extra segments were carried by specimens of a single species,
Chorthippus binotatus, and each of four bivalents could carry two different extra segments. This permitted us to test the effect of different extra segments on chiasma distribution on the same bivalent. Two bivalents $\left(M_{5}\right.$ and $\left.M_{7}\right)$ carried extra segments with a similar distal location, while the two other $\left(M_{6}\right.$ and $\left.S_{8}\right)$ carried extra segments with different locations. With the exception of the euchromatic E-segment on the $\mathbf{M}_{6}$, all remaining extra segments were heterochromatic but with various $\mathrm{C}$-banding reactions according to the patterns described in Camacho et al. (1984). The first conclusion that can be made from our analyses of chiasma distribution on bivalents with and without extra segments in Ch. binotatus is that all extra segments do affect chiasma distribution on the bivalent carrying them, independently of their nature, size, chromosomal location and C-banding reaction, chiasmata being preferentially located in the furthest chromosome regions from the extra segment. This is consistent with former observations on heterogeneous sample of extra segments (Camacho et al., 1984; Navas-Castillo et al., 1985; John and King, 1985; de la Torre et al., 1986). Furthermore, a dependence of the intensity of the chiasma redistribution on the size of the extra segment is demonstrated by our present results. The best bivalents to test this are the $M_{5}$ and $M_{7}$ which possess two different extra segments with the same distal location, those on the $\mathbf{M}_{7}$ being only slightly different in size and those on the $\mathbf{M}_{5}$ being very different. While the extra segments on the $\mathbf{M}_{7}$ produce comparable chiasma redistributions, those on the $\mathbf{M}_{5}$ produce significantly different ones. Thus while the presence of both extra segments determines a significant decrease

Table 4 Chiasma distribution in BB, BD and BP $S_{8}$ bivalents. P: proximal, I: interstitial, D: distal

\begin{tabular}{lllrl}
\hline $\begin{array}{l}\text { Type of } \mathrm{S}_{8} \\
\text { bivalent }\end{array}$ & $\begin{array}{l}\text { Chiasma location } \\
\text { P }\end{array}$ & I & D & $\begin{array}{l}\text { Total diplotene } \\
\text { cells analysed }\end{array}$ \\
\hline BB & $8(2 \cdot 77 \%)$ & $58(20 \cdot 07 \%)$ & $223(77 \cdot 16 \%)$ & 289 \\
BD & $6(13 \cdot 95 \%)$ & $14(32 \cdot 56 \%)$ & $23(53 \cdot 49 \%)$ & 43 \\
BP & - & $5(7 \cdot 69 \%)$ & $60(92 \cdot 31 \%)$ & 65 \\
\hline
\end{tabular}


of distal chiasmata, the small extra segment increases very much the frequency of interstitial chiasmata and only slightly that of proximal ones. Contrarily, the bivalents carrying the large extra segment show significant increases of proximal chiasmata. Thus, the larger the extra segment is, the further chiasma is located on the carrier bivalent.

\section{REFERENCES}

CABRERo, J., NAVAS-CASTILlo, J. AND CAMACHO, J. P. M. 1986. Effects of supernumerary chromosome segments on the activity of nucleolar organiser regions in the grasshopper Chorthippus binotatus. Chromosoma, 93, 375-380.
CAMACHO, J. P. M., VISERAS, E., NAVAS, J. AND CABRERO, J. 1984. C-heterochromatin content of supernumerary chromosome segments of grasshoppers: detection of an euchromatic extra segment. Heredity, 53, 167-175.

DE LA TORRE, J., LÓPEZ-FERNÁNDEZ, C., NICHOLS, R. AND GOSÁlVEZ, J. 1986. Heterochromatin readjusting chiasma distribution in two species of the genus Arcyptera: The effect among individuals and populations. Heredity, 56, 177-184.

JOHN, B. AND KING, M. 1985. The inter-relationship between heterochromatin distribution and chiasma distribution. Genetica, 66, 183-194.

NAVAS-CASTILlo, J., CABRERo, J. AND CAMACHO, J. P. M. 1985. Chiasma redistribution in bivalents carrying supernumerary chromosome segments in grasshoppers. Heredity, 55, 245-248. 